\title{
Reverse Logistics: An analysis of the discarding of overdue supermarket products in the city of Petrolina-PE
}

\section{Jakeline Gomes da Silva ${ }^{1}$, Marcos Paulo Siqueira da Silva ${ }^{2}$, Leonardo Guerra Maia ${ }^{3}$, Kamilla Rayane Brito Souza ${ }^{4}$}

1,2,3,4 Universidade Federal do Vale do São Francisco (UNIVASF). Av. José de Sá Maniçoba, S/N - Centro, Petrolina - PE.

Email: jakeline_gomes16@hotmail.com, mpss_siqueira@hotmail.com, leoguerramaia@hotmail.com, amillabrito.ep@gmail.com

\author{
Received: January $07^{\text {th }}, 2019$ \\ Accepted: January $20^{\text {th }}, 2019$ \\ Published: March $31^{\text {th }}, 2019$ \\ Copyright (C2016 by authors and \\ Institute of Technology Galileo of \\ Amazon (ITEGAM). \\ This work is licensed under the \\ Creative Commons Attribution \\ International \\ License (CC BY 4.0). \\ http://creativecommons.org/licenses/by/4.0/

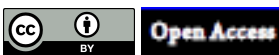

\section{ABSTRACT}

The purpose of this article is to determine the destination given by the supermarkets of Petrolina / PE food products with expiry date close to expiration, in addition to identifying whether or not they use reverse logistics and the access given to them by the industries / distributors to this important tool that aims to help in the correct destination of these types of products, being of fundamental importance for the increase of the margin of profit and the reduction of the operational cost. In recent years, the increase in the use of the reverse logistics tool has been mainly due to the adequacy of the current sanitary legislation, thus making the correct destination of expired food, thus avoiding the fines of the inspection agencies, and directly influencing the costs and profits of traders.

Keywords: logistics, validity, product, supermarkets, destination.

\section{Logística reversa: Uma análise do descarte dos produtos vencidos dos supermercados na cidade de Petrolina-PE}

\section{RESUMO}

Este artigo tem por objetivo apurar a destinação dada pelos supermercados de Petrolina/PE as mercadorias de gênero alimentício com prazo de validade próximos da expiração, além de identificar se os mesmos fazem uso ou não da logística reversa e o acesso dado a eles pelas indústrias/distribuidores a esta importante ferramenta que visa auxiliar na correta destinação destes tipos de produtos, sendo de fundamental importância para o aumento da margem de lucro e a diminuição do custo operacional. Nos últimos anos o aumento da utilização da ferramenta logística reversa, tem se dado principalmente para a adequação a legislação sanitária vigente, realizando assim a destinação correta dos alimentos com prazo de validade expirado, evitando desta forma as multas dos órgãos fiscalizadores, e influenciando diretamente nos custos e no lucro dos comerciantes.

Palavras-Chave: logística, validade, produto, supermercados, destinação.

\section{INTRODUÇÃO}

Com as mudanças que o Brasil vem sofrendo, no que se refere ao cenário econômico e político, percebe-se que são seguidas conjuntamente com elas as modificações na sociedade no que se refere aos hábitos de consumo.

Essa realidade remete ao fato de que o consumo das pessoas passou a ser de consumo por necessidade para o simples alcance do desejo de possuir e de até mesmo o simples ato de comprar. O poder aquisitivo, e até mesmo as facilidades de crédito disponibilizadas as pessoas foram fatores impulsionadores dessa situação. Nessa perspectiva, [1] fala que no que concerne a ampliação do consumo de alimentos industrializados, por exemplo, houve aumento no consumo desses produtos, gerando "grande volume de embalagens descartadas, que especificamente, representam grande volume e problema ambiental sob vários aspectos" [1].

Entretanto, em épocas de crise, esse cenário se inverte: as pessoas compram menos e buscam formas alternativas para suprir suas necessidades e desejos. Diante dessas ações, as empresas também buscam se adequar ao novo cenário. Um exemplo disso está no setor alimentício. Segundo [2] essas mudanças que estão acontecendo no cenário econômico e político do país estão levando as empresas a explorarem soluções para a geração de renda, sendo elas essenciais para a 
manutenção da própria empresa e que proporcione sustentabilidade.

Vale salientar que com grandes quantidades de resíduos produzidos pelo homem, mesmo em épocas de recessão, o governo instituiu instrumentos por meio da política nacional de resíduos sólidos (PNRS), lei 12.305/10, dos quais se destaca a logística reversa [3].

Esse instrumento, segundo [4] "dá condições reais de garantir a posse do produto, por parte do consumidor, no momento desejado". Nessa perspectiva, a logística reversa se tornou um importante instrumento para as empresas no que se refere ao descarte dos resíduos sólidos. Entende-se que, para o presente estudo, resíduos sólidos significam materiais, substâncias ou objetos descartados, que são resultantes de atividades humanas na sociedade [5].

Os supermercados, por exemplo, fazem parte dos canais de distribuição, que passaram a ter consideráveis volumes de resíduos, como embalagens plásticas, papel e principalmente produtos que ultrapassaram a sua validade.

Nesse contexto, o presente trabalho busca investigar quais os destinos adotados pelos grandes supermercados da cidade de Petrolina-PE no que se refere ao descarte de produtos que já exauriram seu período de validade.

Para tanto, o presente estudo encontra-se dividido em quatro partes: referencial teórico, que foi necessário para fundamentação da pesquisa, os procedimentos metodológicos utilizados e, os resultados encontrados e por fim uma análise crítica das informações coletadas.

\section{CONSIDERAÇÕES SOBRE LOGÍSTICA}

“A concepção logística de agrupar conjuntamente as atividades relacionadas ao fluxo de produtos e serviços para administra-las de forma coletiva, é uma evolução natural do pensamento administrativo" [6].

De acordo com [7], a logística pode ser entendida como o conjunto de todas as atividades de movimentação e armazenagem necessárias, de modo a facilitar o fluxo de produtos do ponto de aquisição da matéria-prima até o ponto de consumo final, como também dos fluxos de informação que colocam os produtos em movimento, obtendo níveis de serviço adequados aos clientes, a um custo razoável.

Os serviços de transportes e armazenagem de materiais são importantes no comércio internacional, visto que, as distâncias físicas entre fornecedor e cliente estão aumentando cada vez mais, entretanto, a distância temporal tem diminuído conforme aumenta a competitividade entre setores da economia global e as exigências dos consumidores.

Vale salientar que não é só no comércio internacional que se verifica a importância da gestão dos suprimentos: no mercado interno dos países, a gestão logística, deve ser considerada elemento estratégico para o desenvolvimento econômico. Estratégias de marketing e distribuição, por exemplo, são cada vez mais objeto de interesse das empresas na busca por novos mercados. As empresas, independente do seu porte, devem vislumbrar no estudo das estratégias logísticas, diferenciais de mercado necessários para a sua expansão.

A definição de Logística nem sempre é completamente conhecida por parte das pessoas que se utilizam dela. A impressão inicial, de que logística engloba meramente a operação de transporte de mercadorias, já não é mais considerada. [8] ensina que logística empresarial tem a preocupação principal de suportar a produção com a disponibilização de matérias primas no lugar e no momento necessários, distribuição dos produtos acabados no ponto de venda, visto que esses são os elos entre a indústria e o consumidor final, e a redução de custos com melhoria da eficiência através da correta gestão dos fluxos entre os fornecedores e os clientes.

A definição de logística mais comumente aceita e propagada na literatura é a da entidade americana Council of Supply Chain Management Professionals (CSCMP), formada por profissionais da logística, educadores e pesquisadores da área.

A parte do gerenciamento da cadeia de abastecimento que planeja, implementa e controla de forma, eficiente e eficaz o fluxo direto e reverso, a armazenagem de mercadorias, os serviços e as informações relacionadas entre o ponto de origem e o ponto de consumo, a fim de atender às necessidades dos clientes.

Segundo [9], na logística integrada, todas as funções desde o abastecimento da empresa até a distribuição física dos seus produtos - estão integradas a um único sistema: a cadeia de suprimentos. Todo o processo de planejamento e execução das atividades logísticas deve ter o cliente como origem e destino, pois um sistema logístico integrado só pode funcionar de maneira eficiente se as demandas do cliente puderem ser satisfeitas. Para [10], "não há valor para o produto até que ele seja colocado nas mãos do consumidor ou comprador no tempo e no local em que é necessário".

Assim, segundo [4] a moderna Logística procura incorporar:

- Prazos previamente acertados e cumpridos integralmente, ao longo de toda a cadeia de suprimento;

- Integração efetiva e sistêmica entre todos os setores da empresa;

- Integração efetiva e estreita (parcerias) com fornecedores e clientes;

- Busca da otimização global, envolvendo a racionalização dos processos e a redução de custos em toda a cadeia de suprimento;

- Satisfação plena do cliente, mantendo nível de serviço preestabelecido e adequado.

\section{LOGÍSTICA REVERSA}

Como exposto anteriormente, os resíduos sólidos sejam eles comerciais, industriais, domésticos, hospitalares tem sido um grave problema ambiental, social e econômico para a sociedade atual. Possíveis soluções para amenizá-lo são cada vez mais desejadas, uma vez que é praticamente impossível dar o fim adequado para todo resíduo que geramos diariamente.

No art. $3^{\circ}$ da lei 12.305/10, encontra-se o conceito de logística reversa:

Instrumento de desenvolvimento econômico e social caracterizado por um conjunto de ações, procedimentos e meios destinados a viabilizar a coleta e a restituição dos resíduos sólidos ao setor empresarial, para reaproveitamento, em seu ciclo ou em outros ciclos produtivos, ou outra destinação final ambientalmente adequada [5].

A logística reversa, segundo [1] "pode contribuir para o desempenho da empresa ao possibilitar um aproveitamento do que foi gerado e seria descarte, um aproveitamento econômico." Em síntese, ao levar os materiais do ponto de consumo ao ponto de origem. Intitula-se de "logística reversa", 
o reaproveitamento e reciclagem do material que seria descartado, que pode ser visto como uma possibilidade de reduzir os custos ou até aumentar o lucro de quem a pratica. A logística reversa busca a reutilização dos produtos através de operações de coleta, desmontagem e reprocessamento de materiais ou peças a fim de assegurar uma estratégia de preços competitivos e engajamento ambiental [11].

Também é caracterizada como uma atividade de gestão de materiais necessária para realizar a recuperação do produto, movimentação de materiais e redução na fonte [12].

No que se refere à regulamentação dos resíduos sólidos no Brasil, foi intitulada a Política Nacional de Resíduos Sólidos (PNRS), que provocou uma mudança na postura do Conselho Nacional do Meio Ambiente (CONAMA) em relação à normatização da área de resíduos [13].

Com a aprovação da PNRS os fabricantes, distribuidores, importadores e comerciantes de agrotóxicos, pilhas e baterias, pneus, óleos lubrificantes, lâmpadas fluorescentes, de vapor de sódio e mercúrio e de luz mista, produtos eletrônicos e seus componentes, estão obrigados a desenvolver um sistema de logística reversa para o retorno de produtos e embalagens no final da vida útil, que independe do serviço público de limpeza urbana. Além disso, esta normativa determina que a gestão dos resíduos seja de responsabilidade de todos: governo federal, estados, municípios, empresas e sociedade [13].

É importante lembrar, como mostram [14], que a maior parcela dos resíduos que retornam para as atividades de reciclagem no Brasil volta pelo trabalho dos catadores de materiais recicláveis.

Diante do exposto, a logística reversa pode ser definida como o planejamento, a operação do fluxo e de sistemas de informação logística, e também seus controles, para o retorno de bens por meio de diversos canais reversos. Ela agrega valor de diversas naturezas: econômica, como melhoria na competitividade e apreciáveis retornos financeiros, ecológica, preservando e diminuindo os impactos negativos ambientais tais como: menos uso de água e energia, diminuição de lixões e aterros, controle legal, logístico, impacto na imagem, entre outros [15].

Para [16] o conceito de logística reversa foi se aperfeiçoando ao longo das últimas décadas, não só enquanto definição, como também no que diz respeito às atitudes e a sua abrangência. Desde o início ela era vista apenas como uma distribuição, porém passou a ganhar importância e a se fazer presente com mais responsabilidade em todas as atividades logísticas relacionadas aos retornos de produtos. Nesse sentido surge o termo Green Supply Chain Management (GSCM).

Para [11] as práticas do GSCM, se alinhados à estratégia de operações da organização, podem contribuir não somente nas questões ambientais mais também no incremento do inovação e na eficiência operacional. GSCM é uma abordagem moderna de gestão ambiental e tem como pressuposto que as empresas não agem sozinhas, mas sim se interligando desde fornecedores de matéria - prima até os consumidores finais, formando as chamadas cadeias de suprimentos, que devem estar preocupadas em atender as exigências do mercado com a adoção de princípios de gestão ambiental [17].

No Brasil, a GSCM aparece em pesquisas de logística reversa e sobre impactos ambientais, na tentativa de enfatizar o "verde". Mesmo se mostrando como grande oportunidade para agregar valor, minimizar os impactos no processo de produção, gerar inovações de produto e/ou processo e aumentar a competitividade, a gestão sustentável da cadeia de suprimentos ainda é um tema pouco explorada no Brasil [18].

As principais causas do crescimento dos resíduos sólidos se dão pela diminuição do ciclo de vida dos produtos e pelo uso crescente de materiais descartáveis. A logística reversa potencializa todas as soluções para gerenciamento de resíduos sólidos, ela acaba com o antiquado conceito de "fim da linha" (end-of-pipe), segundo o qual a vida dos produtos tem começo (projeto e produção), meio (uso) e fim (lixões e aterros). A linha virou um círculo: hoje em dia, seu fim coincide com o início e o retoma. Os materiais dos produtos usados, antes sempre chamados de lixo, agora são tidos como matéria-prima para uma nova geração de produtos [16].

\section{III.1 RESÍDUOS SÓLIDOS}

A geração de resíduos é um dos grandes problemas deste século, isso se dá, pelo crescimento das cidades e seus habitantes, o que contribui para que a produção de lixo cresça numa escala considerável. Além do aumento da poluição do solo e das águas, esse fenômeno, traz como consequências problemas de saúde pública e ao meio ambiente. Assim, governantes do mundo inteiro têm se deparado com o problema da destinação final do lixo e buscam alternativas para reaproveitamento dos resíduos, dentre elas, a coleta seletiva, a compostagem e a reciclagem. Tais fatos demandam o estabelecimento de políticas integradas de gerenciamento de resíduos sólidos urbanos, desde a sua geração até a disposição final, com envolvimento dos governantes e da sociedade.

Para [19] conceituam "resíduos sólidos" como: Resíduos nos estados sólido e semi-sólido, que resultam de atividades de origem industrial, doméstica, hospitalar, comercial, agrícola, de serviços e de varrição. Ficam incluídos nesta definição os lodos provenientes de sistemas de tratamento de água, aqueles gerados em equipamentos e instalações de controle de poluição, bem como determinados líquidos cujas particularidades tornem inviável o seu lançamento na rede pública de esgotos ou corpos de água, ou exijam para isso soluções técnicas e economicamente inviáveis em face à melhor tecnologia disponível [19].

A Política Nacional de Resíduos Sólidos, Lei no 12.305/2010, no artigo 13, traz a classificação para os resíduos sólidos quanto à origem e periculosidade, assim apresentados:

\section{- Quanto à origem:}

a) Resíduos domiciliares: os originários de atividades domésticas em residências urbanas;

b) Resíduos de limpeza urbana: os originários da varrição, limpeza de logradouros e vias públicas e outros serviços de limpeza urbana;

c) Resíduos sólidos urbanos: os englobados nas alíneas "a" e "b";

d) Resíduos de estabelecimentos comerciais e prestadores de serviços: os gerados nessas atividades, excetuados os referidos nas alíneas "b", "e", "g", "h" e "j";

e) Resíduos dos serviços públicos de saneamento básico: os gerados nessas atividades, excetuados os referidos na alínea "c";

f) Resíduos industriais: os gerados nos processos produtivos e instalações industriais;

g) Resíduos de serviços de saúde: os gerados nos serviços de saúde, conforme definido em regulamento 
ou em normas estabelecidas pelos órgãos do Sisnama e do SNVS;

h) Resíduos da construção civil: os gerados nas construções, reformas, reparos e demolições de obras de construção civil incluída os resultantes da preparação e escavação de terrenos para obras civis;

i) Resíduos agrossilvopastoris: os gerados nas atividades agropecuárias e silviculturas, incluídos os relacionados a insumos utilizados nessas atividades;

j) Resíduos de serviços de transportes: os originários de portos, aeroportos, terminais alfandegários, rodoviários e ferroviários e passagens de fronteira;

k) Resíduos de mineração: os gerados na atividade de pesquisa, extração ou beneficiamento de minérios;

- Quanto à periculosidade:

a) Resíduos perigosos: aqueles que, em razão de suas características de inflamabilidade, corrosividade, reatividade, toxicidade, patogenicidade, carcinogenicidade, teratogenicidade e mutagenicidade, apresentam significativo risco à saúde pública ou à qualidade ambiental, de acordo com lei, regulamento ou norma técnica;

b) Resíduos não perigosos: aqueles não enquadrados na alínea "a" (Lei no 12.305, de 12 de agosto de 2010).

Nisso, lixo é uma palavra que tem origem latina e significa cinzas ou lixívia. "A denominação "resíduo sólido" pode ser desdobrada em "resíduo", que significa o que sobra de determinadas substâncias, e em "sólido", para diferenciação da palavra entre gases e líquidos”[20].

$\mathrm{Na}$ literatura podem ser encontradas diversas classificações para os resíduos sólidos, quanto às características físicas, à composição química e quanto à origem. A Associação Brasileira de Normas Técnicas - ABNT, NBR 10004, de 2004, classifica os resíduos em: Classe I, ou perigosos, e Classe II, ou não perigosos.

A Política Nacional de Resíduos Sólidos, Lei no 12.305/2010, no artigo 13, traz a classificação para os resíduos sólidos quanto à origem e periculosidade. No Brasil, segundo a Lei $\mathrm{n}^{\circ}$ 12.305, de 02 de agosto de 2010, que instituiu a Política Nacional de Resíduos Sólidos, resíduos sólidos são definidos como: [...] material, substância, objeto ou bem descartado resultante de atividades humanas em sociedade, a cuja destinação final se procede, se propõe proceder ou se está obrigado a proceder, nos estados sólido ou semissólido, bem como gases contidos em recipientes e líquidos cujas particularidades tornem inviável o seu lançamento na rede pública de esgotos ou em corpos d'água, ou exijam para isso soluções técnicas ou economicamente inviáveis em face da melhor tecnologia disponível; (Lei $\mathrm{n}^{\circ} 12.305$, de 12 de agosto de 2010).

No contexto brasileiro, a Política Nacional dos Resíduos Sólidos prevê o controle na geração de resíduos, tendo como proposta a prática de hábitos de consumo sustentável e um conjunto de instrumentos para propiciar o aumento da reciclagem e da reutilização dos resíduos sólidos (aquilo que tem valor econômico e pode ser reciclado ou reaproveitado) e a destinação ambientalmente adequada dos rejeitos (aquilo que não pode ser reciclado ou reutilizado). Este regulamento instituiu a responsabilidade compartilhada entre os fabricantes, importadores, distribuidores, comerciantes, cidadãos e titulares de serviços de manejo dos resíduos sólidos urbanos na logística reversa dos resíduos e embalagens pós-consumo, podendo ser um importante vetor para mudanças das estratégias competitivas das empresas localizadas no Brasil. Pela Lei, tanto o setor público quanto às empresas locais $\mathrm{e}$ multinacionais deverão se adequar para adotar práticas de GSCM, em consequência da Logística Reversa [17].

\section{METODOLOGIA DA PESQUISA}

Por se tratar de uma análise sobre o que acontece na prática de grandes supermercados de um município, no que se refere aos métodos de descartes de produtos vencidos, utilizouse da abordagem qualitativa elencada por [21]. $\mathrm{O}$ autor menciona que essa abordagem é o "meio para explorar e para entender o significado que os indivíduos ou os grupos atribuem a um problema social ou humano" [21].

Nessa perspectiva, a pesquisa caracteriza-se ainda como exploratória, tendo em vista a tentativa de identificar se as empresas estudadas utilizam da logística reversa como instrumento de descarte dos produtos que expiraram a sua data de validade.

Diante disso, a amostra da pesquisa se classifica como não probabilista, tendo em vista que as informações coletadas se referem apenas aos estabelecimentos que se dispuseram a participar, totalizando três supermercados de grande porte, dois supermercados de médio porte e um atacadão.

Para o alcance do objetivo proposto utilizou-se de uma entrevista, pois segundo [22] "um procedimento utilizado na investigação social, para a coleta de dados ou para ajudar no diagnóstico ou no tratamento de um problema social". Uma vez que definido esse método de pesquisa qualitativa como meio para coletar e analisar as informações, precisou-se estruturar um roteiro, a fim de possibilitar a todos os entrevistados responderem as mesmas perguntas [22].

\section{ANÁLISE DOS RESULTADOS}

Os supermercados analisados encontram-se na cidade de Petrolina, localizada no Estado de Pernambuco. Buscou-se mensurar o uso do instrumento da logística reversa de produtos com prazo de validade expirado. Outras informações foram repassadas pelos entrevistados, tendo em vista suas explicações para utilização dos métodos de descartes utilizados.

No tocante aos volumes de compras e vendas, ficou evidente que os estabelecimentos com maiores volumes tem maior facilidade na hora de negociar a substituição dos produtos vencidos, haja vista que em alguns estabelecimentos menores não havia se quer o conhecimento desta prática da substituição.

Com relação às condições oferecidas pelas indústrias ou pelos distribuidores, foi verificado que produtos de marcas menos conhecidas facilitavam o acesso à substituição dos produtos vencidos, uma vez que é de seu interesse ter os seus produtos expostos no maior número de pontos de venda possível, a fim de tornar mais conhecido o seu produto. De forma contrária, os produtos de marca mais conhecida, dificultam o acesso à troca, uma vez que é do interesse do lojista ter esses produtos em suas prateleiras, por terem uma maior saída e um maior valor agregado de margem.

O controle dos produtos a vencer, em todos os estabelecimentos é feito pelos encarregados dos setores e pelos "repositores". A estratégia de escoamento deste tipo de produto também é o mesmo: realização de ofertas, destacando o produto em pilhas ou nas pontas dos corredores, chamando a 
atenção dos consumidores para o preço abaixo do praticado normalmente. A única diferença encontrada entre os estabelecimentos foi que, nos de pequeno porte, o lojista absorve sozinho a diminuição da sua margem de lucro com aquele determinado produto próximo do vencimento, enquanto nos de grande porte, na maioria das vezes, essas promoções são subsidiadas pelas indústrias ou pelas distribuidoras, diluindo assim o seu "prejuízo".

Outra diferença nítida entre "grandes e pequenos", é no descarte dos produtos vencidos, pois o "pequeno" além de não conseguir trocar a maioria dos seus produtos vencidos, tem a responsabilidade de descarta-los dentro das diretrizes legais, aumentando ainda mais o seu custo. Já os de grande porte possuem poucos produtos vencidos, já que conseguem trocar a maioria com fabricantes/distribuidores, que dão a destinação correta, diminuindo assim o seu custo. Em ambos os casos, quando não é possível o retorno do produto ao distribuidor, esses supermercados descartam os produtos no próprio lixo do estabelecimento: isolam os produtos com fitas e/ou papeis filmes e os colocam juntamente com outros resíduos descartados, que serão posteriormente recolhidos pela empresa de coleta de lixo do município, o qual leva esses materiais para aterros sanitários.

Diante disso, apesar do interesse das indústrias de não terem seus produtos vinculados a escândalos de falta de qualidade, intoxicação alimentar, dentre outros, ainda pesa para elas o custo da realização da logística reversa na totalidade dos seus clientes, dando prioridade aos grandes compradores e deixando desassistidos os pequenos comércios. Os comércios por sua vez quando não fazem uso da logística reversa tem não só uma diminuição da margem de lucro dos produtos pelo descarte das unidades vencidas, como também um aumento nos custos operacionais. Essas unidades vencidas tem que ter a destinação correta para atender as legislações sanitárias, e essa destinação no Brasil ainda tem um custo muito alto, pois na maioria das cidades ainda não existe essa estrutura correta de descarte, obrigando os comerciantes a desenvolverem a estrutura, aumentando os custos, ou o que é ainda pode ser pior, gerando o descarte indevido prejudicando assim o meio ambiente.

\section{CONCLUSÃO}

Com o objetivo de identificar como é feito o descarte dos produtos vencidos dos supermercados analisados, considerando ainda se essas empresas realizam a logística reversa, identificou-se que essas organizações além de não utilizarem desse instrumento, os gestores delas não têm conhecimento do que seria a logística reversa. Os representantes dos supermercados não tem noção do que fazem os distribuidores quando eles recolhem os produtos vencidos, e nem tão pouco se preocupam em ter essa informação.

O descarte indevido não só acumula a quantidade de resíduos, como também prejudica o meio ambiente. Os supermercados estudados, quando não conseguem devolver o produto ao fabricante, descartam esses produtos no próprio lixo da empresa, o que proporciona a junção deles com outros resíduos domésticos, que geralmente, no âmbito do municípios são destinados aos aterros sanitários. Esse meio de destinação desses resíduos pode não ser considerado a melhor forma de destinação, tendo em vista que a união de resíduos de composição diferentes pode ocasionar na criação de substancias que degradam o solo e que até mesmo possa causa doenças.
Portanto, infere-se que esses supermercados de grande porte da região, de certa forma, estão utilizando de meios inadequados para destinação dos resíduos gerados pelo alcance da sua data de validade. E juntamente com eles, os supermercados de pequeno porte também. Baseado nisso, entretanto, não se pode concluir que as demais organizações do mesmo ramo seguem essa mesma metodologia de descarte, o que instiga para pesquisas futuras conhecer, através de uma abordagem quantitativa, o destino dado a esses materiais de prazo de validade vencidos.

\section{REFERÊNCIAS}

[1] Araujo, Camila Brunassi, et al. Logística reversa: um estudo em supermercados de cidades do interior paulista. ANAP: São Paulo, v. VI, p. 363. 2010

[2] Veiga, Claudimar Pereira da, et al. Impacto na mudança da política de retorno de produtos alimentícios perecíveis: abordagens ambiental e estratégica. FAPA: Porto Algre/RS, n 18, p. 93-118.

[3] Ministério do Meio Ambiente. Logística reversa. Disponível em: <http://www.mma.gov.br/cidadessustentaveis/residuos-perigosos/logistica-reversa > Acesso em 6 fev. 2018.

[4] Novaes, Antonio Galvão. Logística e gerenciamento da cadeia de suprimentos. Rio de Janeiro: Elsevier. 2007.

[5] Brasil. Lei 12.305, 02 de ago. de 2010. Política Nacional de Resíduos Sólidos. Brasília, DF, fev 2018.

[6] Ballou, Ronald H. Business logistics/supply chain management: planning, organizing, and controlling the supply chain. Pearson Education India, 2007.

[7] Becco, José Eliseu; Nunes, Fernando Ribeiro de Melo. A logística dos supermercados periféricos estudo de caso em Fortaleza com aplicação do benchmarking In: XXIII ENCONTRO NACIONAL DE ENGENHARIA DE PRODUÇÃO, 2003, Ouro Preto, MG, Anais eletrônicos... Ouro Preto: Associação Brasileira de Engenharia de Produção, 2003. Disponível em: <http://www.abepro.org.br/biblioteca/ENEGEP2003_TR0112_ 1389.pdf >. Acesso em: 13 fev. 2018.

[8] Christopher, Martin. Logística e gerenciamento da cadeia de suprimentos: criando redes que agregam valor. 2. ed. São Paulo: Cengage Learning, 2009.

[9] Gomes, Carlos F. S.; Ribeiro, Priscilla C. C. Gestão da cadeia de suprimentos integrada à tecnologia da informação. São Paulo: Pioneira Thomson Learning, 2004.

[10] Arbache, Fernando Saba et al. Gestão de logística, distribuição e trade marketing. 3. ed. Rio de Janeiro: Ed. FGV, 2006.

[11] Drohomeretski, E. Gouvea da Costa, S.Pinheiro de Lima, E. Green supply chain Management: Drivers, barriers and practices within the Brazilian automotive industry. Journal of Manufacturing Technology Management, v. 25, n. 8, p. $1105-$ 1134, 2014. 
[12] Jabbour, A. Souza, C. Oportunidades e desafios para lidar com as barreiras à adoção de práticas de Green Supply Chain Management: Guidelines à luz de um estudo de múltiplos casos no Brasil. Gestão \& Produção, v. 22, n. 2, p. 295-310, 2015.

[13] Lagarinhos, C. Tenório, J. Logística Reversa dos pneus usados no Brasil. Departamento de Engenharia Metalúrgica e de Materiais, Escola Politécnica da Universidade de São Paulo, São Paulo, 2012.

[14] Ribeiro, Daniel Véras \& Morelli, Márcio Raymundo. (2009). Resíduos sólidos problema ou oportunidade?. Rio de Janeiro: Interciência.

[15] Leite, P. R. Logística Reversa: meio ambiente e competitividade. 2. ed. São Paulo: Pearson, 2009.

[16] Paoleschi, B. Logística Industrial e Integrada. São Paulo: Erica, 2008.

[17] Jabbour, A. B. L. S.; Arantes, A. F.; Jabbour, C. J. C. Green supply chain management: mapping the territory. International Journal of Environment and Sustainable Development, v. 12, n. 1, p. 145-167, 2013.

[18] Alves, A. F., Nascimento, L. F. M. Green supply chain: protagonista ou coadjuvante no Brasil?. RAE., São Paulo , v. 54 , n. 5 , p. $510-520,2014$

[19] Tenório, Jorge Alberto. Soares.; Espinosa, Denise Crocce Romano. Controle Ambiental de Resíduos. In: PHILIPPI Jr, Arlindo.; ROMERO, Marcelo Andrade.; BRUNA, Gilda Collet. Curso de Gestão Ambiental. Barueri, SP: Manole, 2004. p. $155-211$.

[20] Ribeiro, H.; Jacobi. P. R.; Besen, G. R.; Gunther, W. M. R; Demajorovic, J.; Viveiros, M. Coleta seletiva com inclusão social: cooperativismo e sustentabilidade. São Paulo: Annablume, 2009.

[21] Creswell, John W. Projeto de Pesquisa: métodos quantitativos, qualitativos e mistos. Tradução de Magda França Lopes. $3^{\circ}$ Ed. Porto Alegre: Artmed, 2010.

[22] Marconi, Marina De Andrade; Lakatos, Eva Maria. Fundamentos da metodologia científica. 5 ed. São Paulo: Atlas, 2003. 